\title{
A Brief Journey into the History of the Arterial Pulse
}

\author{
Nima Ghasemzadeh ${ }^{1,2}$ and A. Maziar Zafari, ${ }^{1,2}$ \\ ${ }^{1}$ Atlanta Veterans Affairs Medical Center, Decatur, GA 30033-4004, USA \\ ${ }^{2}$ Division of Cardiology, Emory University School of Medicine, 1639 Pierce Drive, 322 WMB, Atlanta, GA 30322, USA
}

Correspondence should be addressed to A. Maziar Zafari, azafari@emory.edu

Received 23 December 2010; Revised 26 April 2011; Accepted 20 May 2011

Academic Editor: Julian P. J. Halcox

Copyright (๑) 2011 N. Ghasemzadeh and A. M. Zafari. This is an open access article distributed under the Creative Commons Attribution License, which permits unrestricted use, distribution, and reproduction in any medium, provided the original work is properly cited.

Objective. This paper illustrates the evolution of our knowledge of the arterial pulse from ancient times to the present. Several techniques for arterial pulse evaluation throughout history are discussed. Methods. Using databases including Worldcat, Pubmed, and Emory University Libraries' Catalogue, the significance of the arterial pulse is discussed in three historical eras of medicine: ancient, medieval, and modern. Summary. Techniques used over time to analyze arterial pulse and its characteristics have advanced from simple evaluation by touch to complex methodologies such as ultrasonography and plethysmography. Today's understanding of the various characteristics of the arterial pulse relies on our ancestors' observations and experiments. The pursuit of science continues to lead to major advancements in our knowledge of the arterial pulse and its application in diagnosis of atherosclerotic disease.

\section{Introduction}

"Abu Ali placed his hand on the patient's pulse, and mentioned the names of the different districts and continued until he reached the name of a quarter at the mention of which, as he uttered it, the patient's pulse gave a strange flutter. Then Abu Ali repeated the names of different streets of that district and different houses till he reached the name of a house at the mention of which the patient's pulse gave the same flutter. Finally, he uttered the name of different households of that house until he reached a name at the mention of which that strange flutter resumed. Thereupon he said: This man is in love with such-and-such a girl, in such-andsuch a house, in such-and-such a street, in suchand-such a quarter: the girl's face is the patient's cure" [1].

The above paragraph about Abu Ali Ibn Sina, known by his Latinized name Avicenna, a Persian scholar and a prominent physician of the Middle Ages, illustrating what was called "the quickened pulse of a lover" shows how physicians used the arterial pulse to diagnose certain illnesses in the medieval times. The simplicity of its evaluation had drawn even ancient physicians' attention to itself. Physicians of antiquity used the examination of the pulse not only for diagnosis, but also as an indicator of prognosis.

This paper will review the history of the assessment of pulse from ancient times to the present. The different methodologies for evaluation of arterial pulse characteristics will also be discussed briefly during three different historical eras of medicine, namely, ancient, medieval, and modern medicine.

\section{Ancient Medicine}

\subsection{Indian Medicine.}

"Immediately after pressing the pulse just below the hand joint, firstly, there is a perception of the beating of bayu; secondly, or between bayu and kaph, there is the perception of pitta; thirdly or the last, the perception of the beating of slesma or kaph is gained" [2].

This passage describes the examination and interpretation of the arterial pulse by ancient Indian physicians. Sage 
Kanada (600 BCE), an ancient Indian physician, alchemist, and philosopher, in his book, "Science of Sphygmica", describes a variety of pulses during different physiological and pathological states. Based on his theory, each pulse has three stages, abnormality in any of which reflects diseases of three main humours of the human body, bayu/vata (air), pitta (bile), and kaph/kapha (phlegm) [3].

Ayurveda (knowledge of life) is an ancient medical science that has been originated in the Indian subcontinent and has been practiced since the time of Buddha (500 BCE). The examination of the pulse is an integral part of Ayurvedic medicine. Eight parts of a patient's body are described for physical examination, the first one being the arterial pulse [4]. A full description of the methodology of pulse examination has been described in three categories related to the examiner, the examined, and to the method of examination. A special method was introduced for counting pulse rate in Ayurvedic medicine. Heart rate was counted per "pal" with every 2.5 pal making a minute. Moreover, different pulse rates were described for different age groups in the Ayurveda [5].

2.2. Chinese Medicine. Arterial pulse was studied in China about two and a half thousand years ago. It was first mentioned in the "Internal Medicine Classics, Nei Ching". This manuscript is reported to be written by the Yellow Emperor, Huang Ti (698-598 BC). The principal means of diagnosis employed in the Nei Ching is the physical examination of the arterial pulse. The theory of the pulse is based upon the various stages of interaction between Yin (disease) and Yang (health).

The ancient Chinese physicians had to develop the ability and skill to judge the state of disease-its cause, duration, and prognosis_-by the volume, strength, weakness, regularity, or interruption of the four main varieties of pulse beats (superficial, deep, slow, and quick) [6]. The examination was performed on both wrists, and the best time for examination was early in the morning, in that Yin and Yang were believed to be in balance [7]. The physician would judge the pulse rate based on the ratio between the beating pulse and respiration, four beats to one respiration being normal. The arterial pulse in ancient China was divided into three parts: inch (the one closest to the hand), cubit (the one further up in the arm), and bar (the one in between). Each of the pulse locations in each arm would represent the condition of two different organs of the body [8].

\subsection{Egyptian Medicine.}

"There are canals (or vessels) in it (the heart) to every limb. Now if the priests of Sekhmet or any physician put his hands (or) his fingers on the head, on the hands, or his fingers on the back of the head, upon the two hands, upon the pulse, upon the two feet, he measures the heart, because its vessels are in the back of the head and in the pulse; because its pulsation is in every vessel of every member" [9].
The quotation above suggests that the relationship between the heart beat and the peripheral circulation was conceptualized in ancient Egyptian medicine [10]. It was thought that the arteries contain air, yet the whole concept of circulation was unknown [11]. It was also believed that there are two vascular systems in the human body: the veins, which carry the products of digestion from the digestive tract to the whole body and the arteries, which carry pneuma (air) from lungs to other organs. According to this system, the structure of the heart was inadequately explained. The left side of the heart was accounted for drawing the pneuma from the lungs and pumping it into the arteries of the rest of the body [12].

2.4. Greek Medicine. The word "artery" originated from the Greek word " $\alpha \rho \tau \eta \rho i \alpha$ " which seems to be derived from the word " $\alpha \eta \rho$ " which means air [13]. The examination of the pulse was also described and defined in the Hippocratic writings. Despite Hippocrates (375 BC) being reported to describe the characteristics of the arterial pulse in several conditions such as fever and lethargy in his book on humors $[14,15]$, it was Praxagoras of Kos (340 BC) who was the first physician credited for examining the pulse in ancient Greek literature [16]. Praxagoras discovered that pulsation only occurs in the arteries, not in the veins [17]. His student, Herophilus (335-280 BC), was the first to describe pulsus caprizans, similar to the leap of a goat, an unusual type of pulse with two phases, an initial stroke followed by a stronger one. Another renowned physician of antiquity was Erasistratus (304-250 BC), a contemporary of Herophilus, who was mentioned by Galen as coming very close to the understanding of circulation [16]. Erasistratus stated that the heart and arteries do not move at the same instant, the arteries dilate while the heart contracts, and vice versa. He had recognized that the motion of arteries follows the contraction of the myocardium. Furthermore, Erasistratus explained correctly the dilation of the arteries as a passive expansion of the vessel yet incorrectly assumed that this was caused by the moving of pneuma along the course of the arteries. He and his contemporary physicians (Herophilus and Praxagoras) believed that arteries contain pneuma, while veins contain blood [18]. However, how the pneuma reaches the heart and arteries is not explained in any of the writings of this era [17]. Herophilus believed that dilation of the arteries draws in pneuma from the heart and contraction of the arteries moves it forward and this interplay generates the arterial pulse. In addition, the arterial pulse was thought to be inherent to the arteries and totally different from that of the heart [17]. This theory was believed until Galen, when arteries were discovered to contain blood in addition to air [19].

Herophilus was the first to compare the pulsation of blood vessels to musical rhythm and this theory had an enormous impact on both medical and musical literature until the late middle ages and the Renaissance. Upbeats and downbeats were the units Herophilus used to establish a basic analogy between musical rhythm and pulse rhythm. Herophilus defined the "perceptible time" as the interval of time in which the artery of a newborn would dilate. This 


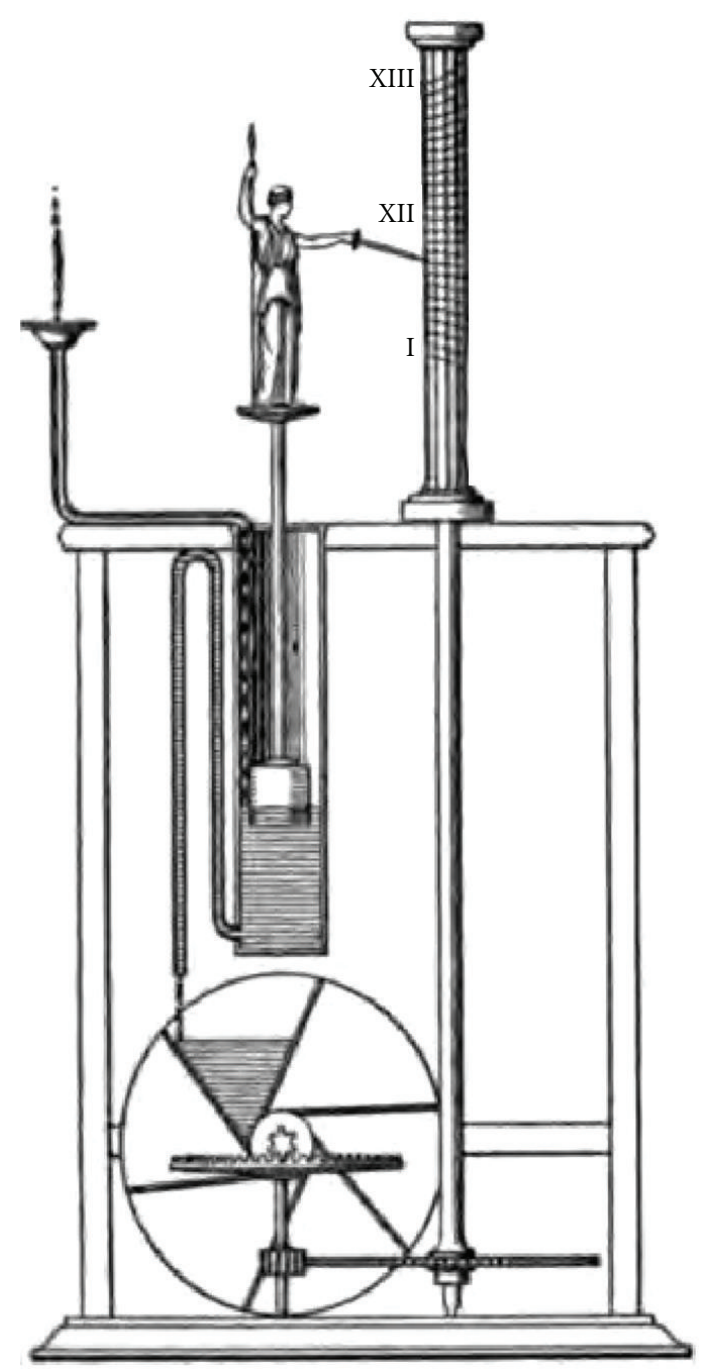

FIGURE 1: Clepsydra or Greek water clock: a portable water clock used by Herophilus for the purpose of arterial pulse examination. This water clock was capable of containing a specified amount of water for natural pulse beats of every age.

perceptible time became the basic unit by which the length of each contraction and dilation was measured, and hence the basic unit by which the pulse rhythm was established [17]. The most interesting part of Herophilus' clinical interest in the pulse is his unique construction of a portable water clock or clepsydra (Figure 1) which he used on his medical rounds to examine the pulse of his patients. This water clock would contain a specified amount of water for natural pulse beats of each age. Although Herophilus recognized the importance of determining the pulse rate, his followers failed to continue his studies in this respect, and there is rarely mention of pulse rate until the fifteenth century.

Archigenes (98-117 CE) discovered the dicrotic pulse as quoted by Horine [16]. It was thought by physicians of the Galenic era that the pulse has many variations, each variation carrying diagnostic or prognostic significance. Archigenes described each arterial pulse as having four characteristics (length, depth, breadth, and speed) and believed that these could be separated by careful palpation [17].

Galen (129-200 CE) thought that the dilation of the artery might be unequal on all sides and a variety of pulses could be felt based on the degree of dilation on each side. For instance, there could be a full upward dilation with a less lateral dilation making a high and narrow pulse. Likewise, there could be a full lateral dilation and a smaller one upward, resulting in a low and broad pulse. He described several types of arterial pulse such as saw-edged pulse, undulating pulse, and worm-like pulse. Other types of arterial pulsation in different temperatures or illnesses including hot pulses and cold pulses, the pulse of pain, inflammation, lethargy, convulsions, jaundice, and even of elephantiasis are described by him [16]. Unlike Erasistratus, Galen argued that the dilation and contraction of both the heart and the arteries are simultaneous. At the time of ventricular systole, the arteries are contracted too, and at the time of diastole they are expanded [20]. Galen described twenty-seven characteristics for a single beat of pulse based on its size, speed, and frequency. Galen's observation of the double-hammer pulse is interesting. He described it quite different from pulsus caprizans as having no interruption between two phases of dilation, the two phases being different in size with the second much smaller than the first [20]. To describe in any further detail all the different types of pulses distinguished by Galen is far beyond the limits of this paper. The principal work dealing with the pulse as such is his treatise in four books entitled "De Pulsuum Differentiis" [21].

\section{Medieval Medicine}

Arterial pulse continued to be one of the most important diagnostic and prognostic signs in medieval medicine. As an example, arterial pulse was mentioned to be valuable in prognostication of epilepsy. A medieval physician who felt the particular pulse of a patient suffering from epilepsy would project that the patient would have a seizure at some point during the natural course of the illness [22].

Avicenna (981-1037 CE) like his predecessors believed that health was based on the interplay of four different humours - blood, phlegm, yellow bile, and black bile [23]. In his treatise on pulse, Avicenna attributed the quality of pulse to the interaction of these four humours. Like Erasistratus, Avicenna thought that the contraction and dilation of both heart and arteries were simultaneous. Furthermore, he believed that arteries contain both blood and pneuma [23]. Following ancient Greek physicians, he also believed in four different movements in arterial pulsation: two movements and two pauses after each movement. However, unlike Galen he argued that the pause following each dilation to be difficult to perceive. He categorized the pulse based on its different characteristics and described different pulse modes in each of these categories:

(1) the size of dilation: strong, weak, and intermediate,

(2) the duration of each movement: short, long, and intermediate, 
(3) the duration of the pause: hurried pulse, sluggish pulse, or intermediate pulse,

(4) the temperature of the pulse: hot, cold, or intermediate,

(5) the compressibility of the artery: easily compressible, incompressible, and moderately compressible,

(6) the fullness or emptiness of the artery: full of humour, containing no humour, and intermediate,

(7) the equality or inequality of force in consecutive beats,

(8) the regularity of the rhythm: regular or irregular (irregularly regular and irregularly irregular).

This classification is similar to what we know currently of the arterial pulse characteristics in arrhythmias such as atrial fibrillation. He described the irregularity both in a single pulsation and in a succession of pulse beats. In terms of irregularities of a single pulse beat, he described premature and dropped beats [24].

Avicenna came close to a general understanding of the various arrhythmias based on the characteristics of the pulse. He described different pulses similar to the pulses being observed in arterial and ventricular arrhythmias [25]. He categorized the arterial pulse more thoroughly than his ancestors. Moreover, he explained three main factors-vital power, resistance, and elasticity - to be of importance in making the size of a pulse beat. This was the first time that concepts like resistance and elasticity were defined in a physiological manner [26]. In describing different pulse rhythms, Avicenna also compared pulse rhythms to musical rhythms [27]. This belief that music is inherent in the beating of the pulse was widely believed throughout the Middle Ages [28]. He described several types of pulses in different age groups and in both genders. Likewise, he revoked different pulses during different physiological and pathological states. The mouse-tail pulse described by Avicenna is similar to what is known as "pulsus alternans" secondary to weakened myocardium. Undulating pulse, dicrotic pulse, and vermicular pulse are a few examples of different types of pulse that were described by him [29, 30]. Based on Avicenna's observations and descriptions of the arterial pulse, it is conceivable that he understood the pulse as a wave, rather than an impact generated by a cylindrical tube, a basic concept that is the foundation for the studies on the pulse wave in modern medicine.

"The pulse which is very abnormal and totally irregular demonstrates that the cause for its abnormal condition migrates".

This quotation from Moses Maimonides (1135-1204 CE) one of the most eminent physicians of the Middle Ages clearly shows that Maimonides understood various arrhythmias based on his findings of the pulse. Similar to his predecessors, he attributed these irregularities to the abnormal constitution of the humours of the heart. Furthermore, he correlated the arterial pulse rhythm with the severity of illness, with more severe illnesses having more irregular pulses [31]. He especially, described the arterial pulse of patients with ascites to be hard and small; however, that of patients with anasarca to be of a fluttering nature [31].

From the days of Hippocrates to the thirteenth century, physicians generally believed that the human heart consisted of four chambers. The lower chambers, the ventricles, were thought to contain blood and the upper chambers to contain air. It was believed that with pores between the two ventricles, venous blood coming from the liver would mix with the air coming from the lungs to make the vital pneuma flourishing the entire body through the arteries. It was Ibn al-Nafis (1213-1288 CE) who discovered the pulmonary circulation of blood. He contradicted the theory of invisible interventricular pores of Galen and others and introduced the pulmonary circulation to medicine [32]. Ibn al-Nafis in his commentary on the anatomy of the Canon, describes the blood to flow from the right chamber of the heart to the lungs via the pulmonary artery, then spreading through the lungs and becoming intermingled with air to create the vital spirit, flowing to the left chambers via the pulmonary veins and subsequently to the entire body [33-37].

\section{Modern Medicine}

"When I first tried animal experimentation for the purpose of discovering the motions and functions of the heart by actual inspection and not by other people's books, I found it so truly difficult that I almost believed with Francastorius, that the motion of the heart was to be understood by God alone. I could not really tell when systole or diastole took place, or when and where dilatation or constriction occurred, because of the quickness of the movement. In many animals this takes place in the twinkling of an eye, like a flash of lighting. Systole seemed at one time here, diastole there, and then all reversed, varied and confused. So I could reach no decision. Finally using greater care every day, with very frequent experimentation, observing a variety of animals, I felt my way out of this labyrinth, and gained information, which I desired, of the motions and functions of the heart and arteries..." [38].

From the 13th until the 16th century, when William Harvey (1578-1657 CE) discovered the greater circulation, there was no major advancement in the understanding of the physiology of the arterial pulse and circulation. Harvey fully described the circular blood flow in the body from the heart to the extremities via arteries and from extremities back to the heart via the venous system [39].

Although the arterial pulse had been an integral guide to reach a diagnosis in antiquity and medieval eras, general concepts of its generation were misunderstood. Both the heart and the arteries were thought to have their own pulsation and to contract simultaneously. It was thought before Harvey's dogma-shattering observations that the arterial pulse is the result of an active force generated in the arterial surface. It was William Harvey who for the first time attributed the generation of the arterial pulse to the contraction of the left ventricle and found the source of the heart beat in the right atrium. He contradicted his forefathers, Galen and Vesalius, in their belief of the origin of the arterial pulse in the arterial 
wall and with his meticulous observations attributed the generation of the arterial pulse to a passive dilation caused by the blood inflow $[40,41]$ and compared this passive dilation of the arteries to the process of inflating a glove by blowing air into it $[42,43]$. Furthermore, for the first time in the history of medicine, Harvey described the arteries and veins to contain nothing but blood [44, 45].

These major discoveries were made with the aid of his meticulous experiments on both humans and animals. In the "Anatomical Studies on the Motion of the Heart and Blood" he comprehensively described his experiments on a variety of animals such as snakes, frogs, snails, shell-fish, and fish [46]. A series of his examinations on the arterial pulse by applying a ligature to the upper extremity clearly shows that Harvey thought of the arterial pulse as a wave and not just an impact $[47,48]$. This conceptualized idea founded on hypothesisdriven and methodological experimentation paved the path for studies of the pulse wave into modern times.

Quantitative hemodynamic measures like stroke volume, cardiac output, ejection fraction are described by him for the first time in the history of medicine [49]. It is evident that his insight into these physiological measures introduced more quantitative rather than qualitative observations into medicine, facilitating more revolutionary discoveries at a faster pace.

By taking a closer look at Harvey's description of the blood circulation, it will become obvious that nothing was known about the capillaries at that time except from an earlier description of the capillaries by Moses Maimonides as the narrow transits communicating arteries with veins. This observation came to the actual discovery of the capillaries by Marcello Malpighi, a professor of anatomy in the seventeenth century [50].

In regard to assessing the frequency of the pulse, the first physician who counted the pulse rate was Herophilus by using his clepsydra. After Herophilus and until the fifteenth century, there is no indication that the pulse rate was actually counted. It is reported that the writings of Bishop Nicholas of Cusa (1401-1464 CE) contains the earliest mention of counting the pulse though the method is not of the kind we use at present time [51]. Pulse rate was compared between a sick and a healthy individual based on the weight of the water flowing from a water clock's narrow aperture into its basin. One hundred pulse beats were counted in different individuals, and the weight of the water flowing to the basin was compared between them making the judgment of health and sickness possible [52]. Galileo's discovery of the pendulum in the early seventeenth century led to the invention of pulsilogy by Santorio Sanctorius (1561-1636 $\mathrm{CE}$ ). This device consisted of a scale of inches and a cord with a movable weight marked with a transverse line (Figure 2). The physician would move the pendulum and note the pulse with his fingers. If the pendulum moved faster than the pulse, the physician would lengthen the line and vice versa until they would coincide, thus showing the pulse rate as the number of inches [51].

A century after the invention of the pulsilogy, John Floyer (1649-1734 CE) counted the pulse rate as we measure it today. He is credited as the first physician to use a pulse

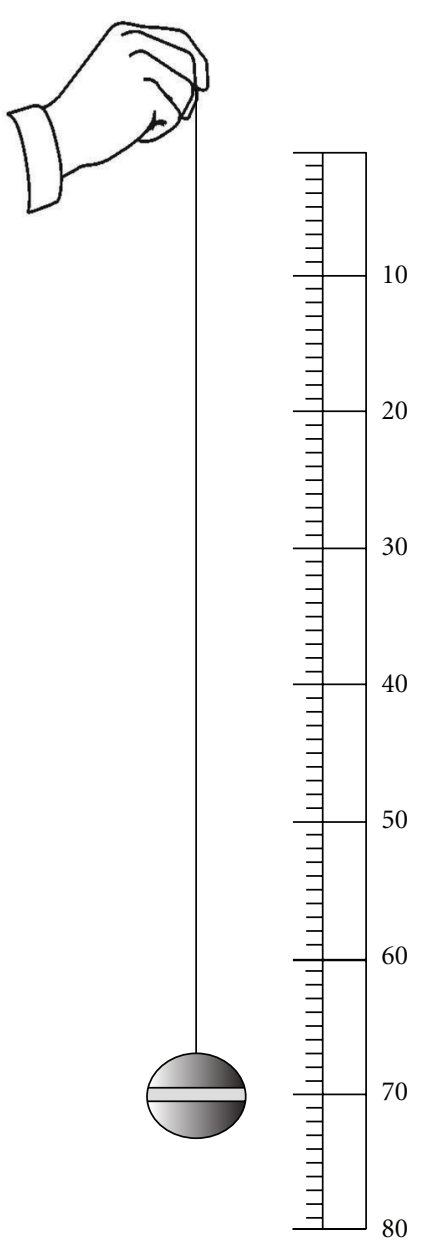

FIgUre 2: Pulsilogy of Sanctorius: this device consisted of a scale of inches and a cord with a movable weight marked with a transverse line. The physician would move the pendulum and note the pulse with his fingers simultaneously. Then, the physician would change the length of the line until the speed of the running pendulum would coincide with the pulse rate, thus showing the pulse rate as the number of inches.

watch that would run for sixty seconds to count the pulse $[53,54]$. After Floyer's introduction of the modern pulse count, physicians started to record their observations in their daily practice based on the number of pulse beats per minute.

Bryan Robinson, an Irish physician (1680-1754 CE), studied the pulse rate in different times during a day, and in people with different heights [55]. Jean Senac (1750-1770 $\mathrm{CE})$, after studying one hundred soldiers, six feet in height, reported that the normal pulse rate ranges from 60 to 90 beats per minute [16]. Other observations were also made such as observations reporting the pulse rate to be a multiple of twelve [56], and those reporting the pulse rate to increase with age [57]. William Falconer (1744-1824 CE) in his great work called "Observations Respecting the Pulse" made numerous tables by which the degree of fever might be determined based on the proportion of the accelerated to the normal pulse [58]. The number of the pulse beats per minute 


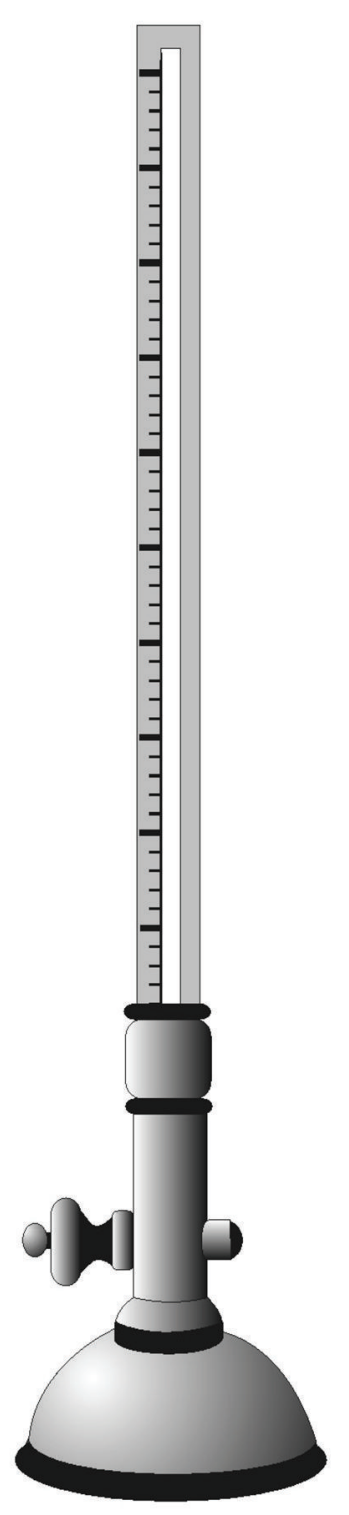

Figure 3: Herrison's sphygmometer: this device was composed of a graduate glass tube containing mercury with a semiglobular ball at one end. With the semiglobular end being placed over an artery, it would show the action of the vessel and the force of its impulse. It was designed in a manner that would enable the examination of the pulse in relation to its force, regularity, and rhythm.

and its characteristics on examination were the only methods of evaluating the pulse beat until the nineteenth century when Jules Herisson invented the sphygmometer (Figure 3). This instrument was composed of a graduated glass tube containing mercury with a semiglobular steel ball at one end. By placing the semiglobular end over an artery, the action of the vessel and the force of its impulse could be shown. This device was designed in a way that would make the examination of the pulse in terms of its force, regularity, and rhythm possible [59].

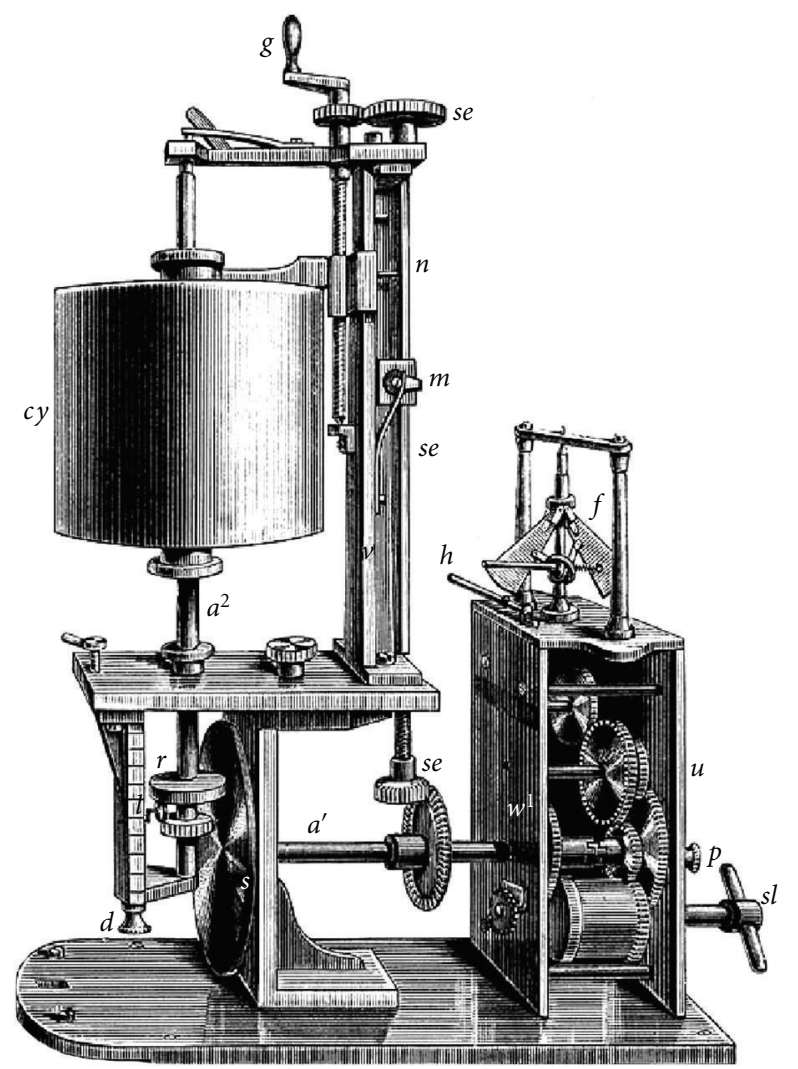

FIGURE 4: Ludwig's kymograph (wave writer): this device was able for the first time to graphically record hemodynamic measures.

The sphygmometer was the first device with the capability of showing the function of the heart and the arteries. Herisson in his book about his sphygmometer, for the first time argued that the sphygmometer was superior to the physicians' touch [60]. He described the sphygmometric findings in different valvular heart diseases like aortic, mitral, and pulmonary valve stenoses [61]. This was the first time that a physician would associate objective findings of a device with inner-body physiologic dynamics.

Twelve years later in 1847, Carl Ludwig, a German physiologist, invented the Kymograph which was a device capable of recording hemodynamic variables (Figure 4) [62]. Ludwig's introduction of the Kymograph in the middle of the nineteenth century greatly influenced the pace of cardiovascular research in future decades.

In 1860, the French physiologist Etienne Marey revised the previously invented sphygmometer and introduced his sphygmograph with graphical recording capabilities (Figure 5).

The first formal study on the arterial pulse wave was done by Marey with the help of his sphygmograph. He depicted the differences in arterial pulse waveforms in the elderly and younger adults [63]. Other examples on studies of the arterial pulse waveforms are Broadbent's lecture on the pulse and its characteristics during the examination [64], and an observation of the pulse rate, temperature, and weight with sphygmographic tracings performed on a man while he 


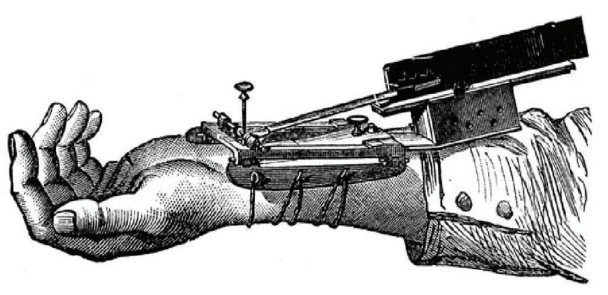

FIGURE 5: Marey's sphygmograph: this device had graphical recording capabilities of the arterial pulse. Applying this device to the wrist would record the motion of the arterial pulse and enable the examiner to interpret rate and rhythm.

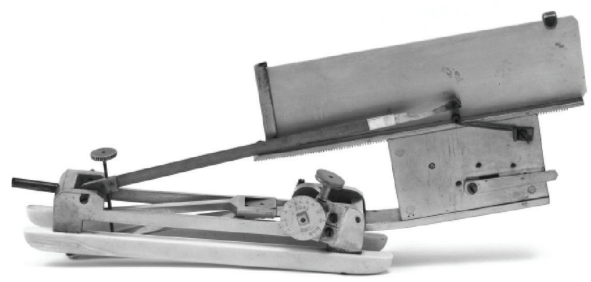

Figure 6: Mahomed's sphygmograph: this device was a revised form of Marey's sphygmograph with an added screw. It was capable of measuring the pressure needed to occlude the arterial wave along its graphical recordings of the arterial pulse wave dynamics.

was walking a long distance by Mahomed (1849-1884 CE), Broadbent's student [65]. This served as a foundation for studies on the effect of ambulation on hemodynamic parameters such as pulse rate. Mahomed revised Marey's sphygmograph by adding a screw, thereby making the measurement of the pressure needed to occlude the arterial wave feasible (Figure 6). He used his revised sphygmograph to study the form and pressure of the pulse wave in several patients with different diseases $[66,67]$. With the aid of his sphygmograph he described high tension in the arterial system and was the first to describe essential hypertension and distinguish it from hypertension caused by glomerulonephritis $[68,69]$. In Figure 7, the graphical demonstration of the arterial pulse wave in asymptomatic patients with arterial hypertension is illustrated by O'Rourke [67]. Graphical recordings of the pulse in the nineteenth and early twentieth century permitted the arterial pulse to be studied as a wave and not just an impact [66]. Hawthorne, an early twentieth century physician made multiple observations based on his findings of the arterial pulse wave using both instruments. He argued that although at times the blood pressure findings may seem to be contradictory using both instruments, these two instruments were actually complementing each other [70]. Several forms of arterial pulse were described based on their sphygmographic characteristics in the twentieth century, that is, the water-hammer pulse, the bisferiens pulse, and the anacrotic pulse [71]. Mahomed's sphygmograph with the capability of quantitatively recording the pressure of the pulse wave led to the introduction of the sphygmomanometer in the late nineteenth century and the cuff sphygmomanometer by Postel-Vinay in 1896 [72]. With the advent of Riva Rocci's cuff sphygmomanometer, graphical tracing of the peripheral pulse wave gradually gave its place to peripheral blood pressure recording $[73,74]$. Pulse wave tracing was difficult and time consuming with often times artefacts on recordings. On the other hand, the cuff would make the interpretation easier by just providing numbers that would reflect cardiac strength (systolic pressure) and arteriolar tone (diastolic pressure) [75]. A multitude of parallel studies and observations were done on the three major characteristics of the peripheral arterial pulse wave, its velocity, its pressure, and its volume. These led to the initiation of studies in clinical pharmacology on the application of certain medications on these physiologic parameters in the current era.

Modern studies on the pulse wave and arterial hemodynamics stem from the pioneering studies of the early modern era. Stephen Hales (1677-1746) in a series of papers called "Statical Essays: Containing Haemostatics" presented his contributions to the arterial hemodynamics before the Royal Society. The following quotation from his third experiment clearly shows the earliest studies on the mechanics of the circulation:

“... But the systole of the ventricle during which that quantity of blood is propelled, being estimated to be done in one third of the space of time between each pulse, the velocity of the blood during each systole will be thrice as much, at the rate of 5211 feet, that is, 0.98 of a mile in an hour, or 86.85 feet in a minute" [76].

Hales's studies were followed by other scientists such as Leonhard Euler who formulated quantitative measures of the arterial hemodynamics. However, he was quite unsuccessful in proposing a formula that could simply show the relationship between the mechanical forces and the dynamic measures of the arterial pulse wave [77]. The idea of viewing the arterial pulse as a series of waves in a frequency domain had been related to the Fourier's heat wave transfer function studies. Similarly, the time domain analysis and the method of explaining the pulse mechanics with the characteristics of single pulse units had originated from the earlier works of Leonhard Euler (1707-1783). Euler's tube laws for arteries unsuccessfully tried to use a nonlinear form of conservation equations to explain the mechanics of the greater circulation. Years later, these were applied by Riemann to the time domain theory of the pulse wave.

Crighton Bramwell a scientist in the early twentieth century was first to introduce the concept of pulse wave velocity (PWV). He described the velocity to vary in proportion to the arterial wall tension and the blood pressure and to be an indirect measure of the arterial wall elasticity. Bramwell and Hill introduced a simple formula by which the arterial elasticity could be calculated from the PWV. With this formula he found a positive correlation between PWV and age and a negative correlation between arterial wall elasticity and PWV [78]. 


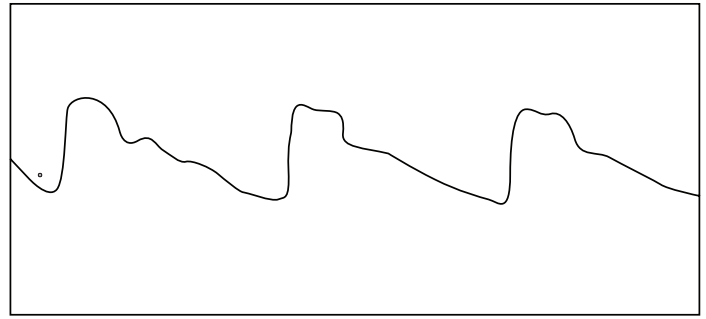

(a) Arterial pulse wave form in a man with arterial hypertension

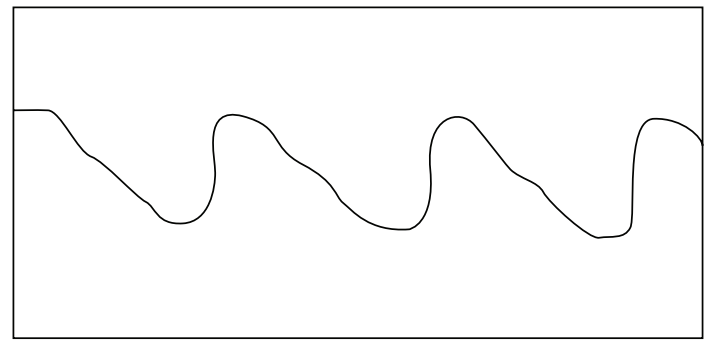

(b) Arterial pulse wave form in a woman with arterial hypertension

FIGURe 7: Graphical depictions of the arterial pulse wave form by Mahomed in an asymptomatic male (a) and female (b) with arterial hypertension. Reproduced from [80].

Bramwell's formula:

Velocity $(\mathrm{m} / \mathrm{sec})$

$=3.57 / \sqrt{ } \%$ increase in volume $/ \mathrm{mmHg}$ increase in pressure.

During the mid-twentieth century, studies on hemodynamics of the arterial pulse wave were followed by the great works of Womersely and Nichols et al. [79, 80]. It is evident that with the advent of digital computers, Fourier's frequency domain analysis gained more popularity amongst scientists. Computers made calculations of the series of pulse wave transfer functions faster and easier. Taylor claimed that a more profitable approach had been made by using the frequency domain theory [81]. However, as time passed, again the time domain theory returned to studies on the dynamics of the arterial pulse wave. O'Rourke has fully described the application of the time domain analysis in clinical medicine and has compared it with the frequency domain. He has shown that modern analysis of the pulse in the time domain supports its historical perspectives and emphasizes the importance of arterial stiffening with age, wave reflection, their effects on the heart and their modification with therapy [82]. Despite all these studies, there is still an ongoing substantial controversy on the best method to be used in the clinical arena [83-85].

Since the invention of the plethysmograph by Schmitt in the mid-twentieth century [86], studies of the pulse wave have proceeded at a faster pace. Several methods have been in the past fifty years for the study of PWV, such as hot-wire sphygmography, impedance plethysmography, applanation

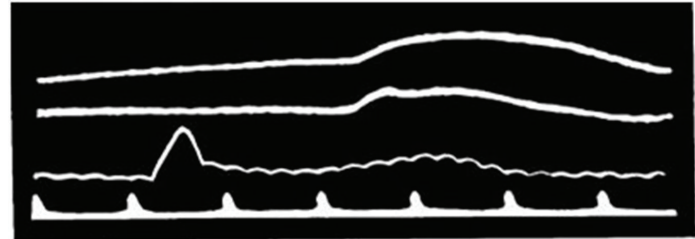

(a)

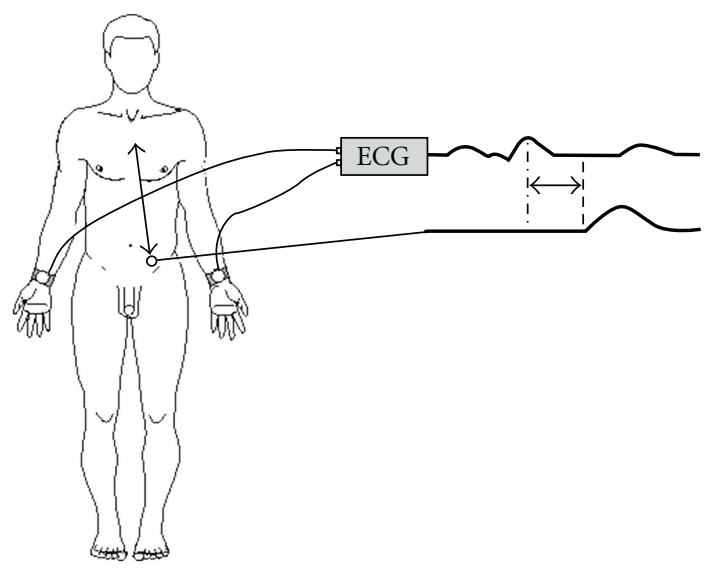

(b)

FIGURE 8: (a) This graph illustrates time marker as the lowest line, cardiogram tracing as the line above that, and femoral pulse waves as the two top tracings. (b) Distance "a" represents the distance between aortic arch and the position of the microphone over the femoral artery "Reproduced from [91] with permission from BMJ Publishing Group Ltd.”

tonometry, and recording the pulse wave using crystal microphones $[87,88]$. While both sphygmography and plethysmography can be used for monitoring the pulse wave and its regularity, plethysmography can offer more technical usages including: peripheral oximetry, blood pressure monitoring and assessment of the adequacy of peripheral circulation as derived from the Allen's test [89]. In the 1960s Simmons and his colleagues applied a strain gauge plethysmograph to one digit and with the help of an amplified electrocardiogram recorded the resistance change caused by entrance of blood into that digit. Pulse waves from eighty normal subjects and patients with a variety of peripheral vascular diseases were recorded and compared in this study. They suggested that this technique could be of importance in the evaluation of peripheral arterial disease and the atherosclerotic changes of the peripheral circulation [90]. Crystal microphones were primarily used for determination of PWV. A crystal microphone would be applied to the groin over the femoral artery and would convert the pulse wave sound to an electric signal. Simultaneous EKG tracing would also be obtained and displayed. The time lag between the peak of the EKG's $\mathrm{R}$ wave and the foot point of the pulse wave would be used to calculate the PWV with inclusion of the distance between the two anatomical points of the patient's body in the equation (Figure 8) [91].

Woolam and his colleagues in 1962 used a crystal microphone for recording the pulse wave. By applying two crystal 
microphones, one to the wrist and the other to the carotid artery they recorded the pulse wave and its velocity travelling along the course of the brachial artery. They demonstrated a higher PWV in diabetic patients. Other studies on the velocity of the arterial pulse wave showed that higher values are in a strong correlation with the atherosclerotic changes of the arteries $[92,93]$.

Gradually, studies of PWV changed from the peripheral circulation to the more reliable studies on the central circulation. Investigators started to study the pulse wave characteristics of the abdominal aorta mainly because it was more reliable, less variable, and more easily reproducible [93]. By using plethysmography for recording hemodynamics of the abdominal aorta, aortic PWV was found to be an important surrogate for stiffness of the coronary vasculature; this was confirmed with angiographic findings of the coronary vessels by Kogure et al. 1988 and Hirai et al. 1989 [94, 95]. In a recent meta-analysis of 17 longitudinal studies, Vlachopoulos and colleagues have found that aortic PSW is an independent predictor for all-cause mortality and cardiovascular outcomes and that risk is especially higher in patients with more baseline cardiac risks [96-99]. Recent studies suggest different effects on central blood pressure compared to peripheral blood pressure by some antihypertensive medications [100]. There remains still a considerable debate on which technology to use for prognostication. Future largescale observational studies are needed to answer this specific question.

Asmar et al. in a study of 56 subjects compared a new automated device with manual calculation for determination of PWV and found that the findings from the two were very close and reproducible [101]. This finding led to the development of three automated devices: Complior (Artech Medical, Pantin, France), Sphygmocor (AtCor Medical, Sydney, Australia), and Arteriograph (TensioMed, Budapest, Hungary). Measuring PWV with Complior requires two pressure transducers that would record carotid and femoral pulse waves simultaneously. With calculation of the time delay between the two points, the machine will be able to provide an estimate for the velocity of the pulse wave. Sphygmocor utilizes a two step approach for calculation of the PWV with a single tonometer applied to femoral and carotid sites one at a time along with simultaneous EKG tracing. Arteriograph is a recently developed computerized device using oscillometric methods to determine PWV. The main principle used with Arteriograph is to record what is called the "return time". Return time is the time difference in milliseconds between the first wave and the reflected systolic pulse wave when cuff pressure is $35 \mathrm{mmHg}$ over systolic blood pressure. Pulse wave velocity is then generated from the return time and the distance travelled by the wave. Arteriograph does not measure the time lag between carotid and femoral impulse. Rajzer and colleagues have compared the aortic PWV measured by these three devices in 64 patients with Stage I or II hypertension and have observed a difference in PWV derived from each method due to different estimation of the travelled distance of the pulse wave [102]. Jatoi and colleagues in a study of 254 untreated hypertensive patients compared PWV derived from Arteriograph with those of Complior and Sphygmocor and found that although the Arteriograph values were in close agreement with those of Complior and Sphygmocor, the techniques are not interchangeable [103]. Other noninvasive methods such as ultrasound and magnetic resonance imaging have been also introduced for the measurement of PWV [104-106]. Using ultrasound, aortic PWV was found to be an independent predictor of cardiovascular risk [107].

Doppler echocardiography with a high-resolution echotracking system is also used to estimate arterial compliance and augmentation index based on carotid artery diameter change [104, 108, 109]. The development of echo-tracking systems for estimation of arterial compliance was inspired by the work of Peterson and colleagues in 1960 who observed that vascular diameter pulse waveforms agree well with the intravascular pressure waveforms [110].

In contrast to applanation tonometry which can be applied to a limited number of peripheral arteries, the arterial distension waves obtained by echo-tracking systems can be recorded from a variety of sites and has an advantage of being very useful in obese patients for whom the applanation tonometry method might not be easily used.

Pulse pressure, another important characteristic of the pulse wave, has been studied extensively in more recent years. Its association with cardiovascular outcomes and its application in clinical pharmacologic studies are of clinical importance. As mentioned previously, with the invention of Riva Rocci's cuff sphygmomanometer in the early twentieth century clinicians made important observations regarding pulse pressure (pulsatile component of blood pressure) which was ultimately found to be an important risk factor for cardiovascular disease [111]. The positive association of pulse pressure with aging and arterial stiffness has also been scrutinized in several studies. The idea of this association was first brought about in the early nineteenth century by O'Rourke and Madhavan et al. who both diagnosed arterial stiffness by examining the characteristics of the arterial pulse waveforms $[112,113]$. The Framingham study is one of the most important studies that has made seminal observations about the variation of blood and pulse pressure in different age groups. Furthermore, brachial pulse pressure was shown in different outcome studies to be a significant risk for developing coronary and carotid events [114-116].

Other than the pulse pressure, both the systolic and the diastolic components have been studied in relation to cardiovascular outcomes. Despite earlier misbelief that only systolic pressure is a predictor of outcome The Multi Risk Factor Intervention Trial (MRFIT) showed that both are independent predictors of cardiovascular outcomes [117].

Augmentation index (AI) as a measure of pulse pressure was first defined by Kelly and his colleagues in 1989. They defined AI for each pulse wave as the ratio of height of the peak above the shoulder of the pulse wave to the pulse pressure using a micromanometer probe over the carotid and radial arteries. They showed that the augmentation index was in direct correlation with age [118]. Several studies have shown an association between AI and increased cardiovascular risk $[96,119-121]$. 
TABLE 1: Instruments used for the examination of the arterial pulse.

\begin{tabular}{ll}
\hline Instrument & Inventor \\
\hline Clepsydra & $\begin{array}{l}\text { Herophilus (Third century BC) } \\
\text { Santorio Sanctorius (Sixteenth-Seventeenth } \\
\text { century) } \\
\text { Pulsilogy }\end{array}$ \\
$\begin{array}{l}\text { Sir John Floyer (Seventeenth-Eighteenth } \\
\text { century) }\end{array}$ \\
Sulse watch & Jules Herisson (Nineteenth century) \\
Kymograph & Carl Ludwig (Nineteenth century) \\
Sphygmograph & Etienne Marey (Nineteeth century) \\
Hemotachometer & Karl Vierordt (Nineteenth century) \\
Plethysmograph & Otto Schmitt (Twentieth century)
\end{tabular}

During the last twenty years, studies on the pathophysiology of atherosclerosis have shown endothelial dysfunction to play an integral role in the development of atherosclerosis in its preclinical stages. Endothelial dysfunction also has been shown to be an independent predictor of cardiovascular outcomes $[122,123]$. Assessment of flow-mediated dilation of the brachial artery by ultrasonography, another characteristic of the arterial pulse wave and an indirect measure of pulse wave volume and arterial stiffness, has been introduced as a measure of endothelial function [124, 125]. Stiffness has been shown to be partly under control of the endothelium, which releases a number of vasoactive mediators. More recently, a reliable, less intensive, and technically simpler method of measuring endothelial dysfunction has been developed called pulsatile arterial tonometry (PAT). Pulsatile arterial tonometry is a novel technique to assess nitric oxide bioavailability and is less operator-dependent than flow-mediated dilation (FMD) for determination of endothelial function and arterial stiffness [126]. This device measures reactive hyperemia of the digits, which correlates with coronary microvascular endothelial function [127, 128]. The presence of coronary endothelial dysfunction is associated with lower PAT values in patients without obstructive coronary artery disease [127]. A linear relationship has been shown between PAT and brachial artery FMD measurements in patients with a variety of traditional risk factors [128].

Some of the most important instruments that have been used for the examination of the pulse throughout the history of medicine are listed with their inventors in Table 1.

\section{Summary and Discussion}

Current knowledge of the arterial pulse has culminated from the beliefs, observations, interpretations, dogmas, and the rejection of dogmas throughout the history of medicine. Our intention with this historical review is to make the reader appreciate how the understanding of the arterial pulse has progressed over the centuries to the present time and give the reader an insight for future developments.

In this paper, we describe the significance of the arterial pulse in clinical practice from ancient to modern eras. Several methodologies for the analysis of pulse wave and its characteristics including velocity, pressure, and volume have been discussed. These methods range from simple examination of the arterial pulse by touch to more complex techniques and devices that are being used and developed. Between all these methods, the only practical devices that have been shown in several studies to impact cardiac outcomes are cuff sphygmomanometer and noninvasive measurement of PWV. Despite its known limitations including limited precision, the cuff sphygmomanometer has held its place in routine evaluation and determination of arterial pulse pressure, globally. Despite the fact that measurement of PWV is recommended by the European Society of Cardiology as a prognostic factor [129], there is still lack of convincing clinical data to select and modify antihypertensive treatment based upon this clinical parameter $[101,130]$.

Scientific progress in arterial biology and physiology continues at a faster pace with the help of advanced technologies, designed by astute clinical observers, hypothesis-driven scientists and technical innovators; this body of work will certainly continue to grow and further our understanding of the arterial circulation.

\section{Acknowledgments}

The authors express their gratitude to Mr. Ted Willi at Emory University School of Medicine's Woodruff Health Sciences Center Library for his generous help in searching for the references of this paper and Mr. Donn Johnson at the Atlanta Veterans Affairs Medical Center, Media Production Services for his technical assistance with the graphical depictions for this paper.

\section{References}

[1] The Chahar Maqala of Nidhami-i-'Arudi-i-Samarqandi, S. Austin and Sons, Hertford, UK, 1899, Anecdote xxxv, translated into English by E. G. Browne.

[2] M. Kanada, The natural movement or beating of the pulse, Gupta KRL, trans, Sage Kanad on Pulse, 1987.

[3] M. Kanada, "The state or movements of the dandaja pulse," Sage Kanad on Pulse, vol. 1, pp. 28-30, 1987, Gupta KRL, trans.

[4] V. Lad, Secrets of the Pulse: the ancient Art of Ayurvedic Pulse Diagnosis, 1996.

[5] V. G. P. Upadhyay, The Science of Pulse Examination in Ayurveda, Sri Satguru Publication, New Delhi, India, 1997.

[6] T. N. Huang, The Yellow Emperor's Classic of Internal Medicine, 1966, translated by I. Veith.

[7] B. Flaws, The Technique of Examining the Pulse. The Secret of Chinese Pulse Diagnosis, Blue Poppy Press, Boulder, Colo, USA, 1st edition, 1995.

[8] J. Wang and L. Wu, The Doctorine of the Pulse. History of Chinese Medicine; Being a Chronicle of Medical Happenings in China from Ancient Times to the Present Period, AMS Press, New York, NY, USA, 2nd edition, 1973.

[9] B. Ebbell, The Papyrus Ebers: The Greatest Egyptian Medical Document, Oxford University Press, London, UK, 1937.

[10] J. Henry, The Edwin Smith Surgical Papyrus, 1984.

[11] J. F. Nunn, Ancient Egyptian Medicine, British Museum Press, London, UK, 1996.

[12] D. J. Furley and J. S. Wilkie, Galen on Respiration and the Arteries, Princeton University Press, Princeton, NJ, USA, 1984. 
[13] C. Vlachopoulos and M. O'Rourke, "Genesis of the normal and abnormal arterial pulse," Current Problems in Cardiology, vol. 25 , no. 5, pp. 301-367, 2000.

[14] J. S. Floyer, The physician's pulse-watch; or, An essay to explain the old art of feeling the pulse, and to improve it by the help of a pulse-watch ... to which is added, an extract out of Andrew Cleyer, concerning the Chinese art of feeling the pulse, S. Smith and B. Walford, London, UK, 1707.

[15] O. C. L'antique, Des Asclepiades a Galien. La circulation et le pouls; histoire, physiologie, séméiotique, indications thérapeutiques, Baillière, Paris, France, 1886.

[16] E. Horine, "An epitome of ancient pulse lore," Bulletin of the History of Medicine, vol. 10, pp. 209-249, 1941.

[17] H. V. Staden, Herophilus the Art of Medicine in Early Alexandria, Cambridge University Press, Cambridge, UK, 1989.

[18] M. Boylan, "Galen: on blood, the pulse, and the arteries," Journal of the History of Biology, vol. 40, no. 2, pp. 207-230, 2007.

[19] R. E. Siegel, Galen's System of Physiology and Medicine, Karger, New York, NY, USA, 1968.

[20] C. R. S. Harris, Galen's Pulse-Lore. The Heart and the Vascular System in Ancient Greek Medicine, from Alcmaeon to Galen, Clarendon Press, Oxford, UK, 1973.

[21] K. Zoupan, De Pulsuum Differentiis Simplicibus, Stanno Schneideriano, Halae Magdeburgicae, 1760.

[22] F. Wallis, "Signs and senses: diagnosis and prognosis in early medieval pulse and urine texts," Social History of Medicine, vol. 13, no. 2, pp. 265-278, 2000.

[23] Avicenna, Mishkāt M. Rag'shināsi, yā, Risālāh dar nabz: Silsilah-i intishārāt-i Anjuman-i Āsār-i Millì, Tehran, Iran, 1951.

[24] L. G. O. C. Bakhtiar, Avicenna SMHCJR, Qanun fi a-t. The canon of medicine (al-Qanun fi'l-tibb). [S.l.], Great Books of the Islamic World, Chicago, Ill, USA, 1999.

[25] Avicenna, Mishkāt M. Rag'shināsi, yā, Risālāh dar nabz: Silsilah-i intishārāt-i Anjuman-i Āsār-i Millì, Tehran, Iran, 1951.

[26] L. G. O. C. Bakhtiar, Avicenna SMHCJR, Qanun fi a-t. The canon of medicine (al-Qanun fi'l-tibb). [S.l.], Great Books of the Islamic World, Chicago, Ill, USA, 1999.

[27] Avicenna, Mishkāt M. Rag'shināsi, yā, Risālāh dar nabz: Silsilah-i intishārāt-i Anjuman-i Āsār-i Millì, Tehran, Iran, 1951.

[28] N. G. Siraisi, "The music of pulse in the writings of Italian academic physicians (fourteenth and fifteenth centuries)," Speculum, vol. 50, pp. 689-710, 1975.

[29] Avicenna, Mishkāt M. Rag'shināsi, yā, Risālāh dar nabz: Silsilah-i intishārāt-i Anjuman-i Āsār-i Millī, Tehran, Iran, 1951.

[30] G. O. C. Avicenna, A Treatise on the Canon of Medicine of Avicenna, Incorporating a Translation of the First Book, edited and translated by O. C. Gruner, Kelley, New York, NY, USA, 1970.

[31] M. Maimonides, F. Rosner, and S. Muntner, The Medical Aphorisms of Moses Maimonides. Studies in Judaica, Yeshiva University Press, New York, NY, USA, 1970.

[32] E. E. Bittar, "A study of ibn Nafis," Bulletin of the History of Medicine, vol. 29, no. 5, pp. 429-447, 1955.

[33] S. I. Haddad and A. A. Khairallah, "A forgotten chapter in the history of the circulation of the blood," Annals of Surgery, vol. 104, no. 1, pp. 1-8, 1936.

[34] C. D. O'malley, "A Latin translation of Ibn Nafis (1547): related to the problem of the circulation of the blood," Journal of the History of Medicine and Allied Sciences, vol. 12, no. 4, pp. 248-253, 1957.

[35] I. A. Khan, S. K. Daya, and R. M. Gowda, "Evolution of the theory of circulation," International Journal of Cardiology, vol. 98, no. 3, pp. 519-521, 2005.
[36] E. E. Bittar, The influence of Ibn Nafis: a linkage in medical history. Ali ibn Abi l-Hazm al-Qarshi ibn al-Nafis (d. 6871288): texts and studies: Frankfurt am Main: Institute for the History of Arabic-Islamic Science at the Johann Wolfgang Goethe University (OCoLC)39660818. 1997:292-296.

[37] E. D. Coppola, The influence of Ibn Nafis: The discovery of the pulmonary circulation: a new approach. Ali ibn Abi l-Hazm alQarshi ibn al-Nafis (d.687/1288): texts and studies: Frankfurt am Main: Institute for the History of Arabic-Islamic Science at the Johann Wolfgang Goethe University. 1997:304-337.

[38] W. F. K. J. Harvey, The Circulation of the Blood and Other Writings, Dent, London, UK, 1963.

[39] E. T. McMullen, "Anatomy of a physiological discovery: William Harvey and the circulation of the blood," Journal of the Royal Society of Medicine, vol. 88, no. 9, pp. 491-498, 1995.

[40] W. Harvey, The works of William Harvey. The Classics of the St. John's Program; Variation: Classics of the St. John's Program, The Sydenham Society, [Ann Arbor, Mich., Edwards Brothers], London, UK, 1943.

[41] W. W. G. Harvey, An Anatomical Disputation Concerning the Movement of the Heart and Blood in Living Creatures, Blackwell Scientific Publications, Oxford, UK, 1976.

[42] W. Harvey and C. D. Leake, Exercitatio Anatomica de Motu Cordis et Sanguinis in Animalibus, R. Lier \& Co., Florence, Italy, 1928.

[43] W. Harvey, An Anatomical Disputation Concerning the Movement of the Heart and Blood in Living Creatures, Blackwell Scientific Publications, Oxford, UK, 1976.

[44] W. Harvey and C. D. Leake, Exercitatio Anatomica de Motu cordis et Sanguinis in Animalibus, R. Lier \& Co., Florence, Italy, 1928.

[45] J. McMichael, "History of artrial fibrillation 1628-1819. Harvey-de Senac-Laennec," British Heart Journal, vol. 48, no. 3, pp. 193-197, 1982.

[46] W. Harvey and C. D. Leake, Exercitatio Anatomica de Motu Cordis et Sanguinis in Animalibus, R. Lier \& Co., Florence, Italy, 1928.

[47] W. W. R. Harvey, The works of William Harvey, The Sydenham Society, London, UK, 1847.

[48] W. Harvey, An Anatomical Disputation Concerning the Movement of the Heart and Blood in Living Creatures, Blackwell Scientific Publications, Oxford, UK, 1976.

[49] W. Harvey, An Anatomical Disputation Concerning the Movement of the Heart and Blood in Living Creatures, Blackwell Scientific Publications, Oxford, 1976.

[50] J. M. S. Pearce, "Malpighi and the discovery of capillaries," European Neurology, vol. 58, no. 4, pp. 253-255, 2007.

[51] N. Moore, "A lecture on the pulse," The Lancet, vol. 150, no. 3875, pp. 1438-1440, 1897.

[52] G. L. Townsend, "Sir John Floyer (1649-1734) and his study of pulse and respiration," Journal of the History of Medicine and Allied Sciences, vol. 22, no. 3, pp. 286-316, 1967.

[53] J. Floyer, The physician's pulse-watch or, an essay to explain the old art of feeling the pulse, and to improve it by the help of a pulse-watch. In three parts. ... By Sir John Floyer, Sam. Smith and Benj. Walford, London, UK, 1707.

[54] W. B. Fye, "Disorders of the heartbeat: a historical overview from antiquity to the mid-20th century," American Journal of Cardiology, vol. 72, no. 14, pp. 1055-1070, 1993.

[55] B. Robinson, Of Muscular Motion, the Motion of the Blood, and Respiration. A Treatise of the Animal Oeconomy, George Grierson, Dublin, Ireland, 1732.

[56] "Diagnosis by the pulse," The Lancet, vol. 40, no. 1024, pp. 87-88, 1843. 
[57] “The pulse,” The Lancet, vol. 22, no. 555, pp. 116-117, 1834.

[58] W. Falconer, Table of the different rates of natural pulses from 40 to 130 in a minute. Observations respecting the pulse; intended to point out with greater certainty, the indications which it signifies; especially in feverish complaints, T. Cadell, junior, and W. Davies, (successors to Mr. Cadell), London, UK, 1796.

[59] "Measurement of the pulse: the sphygmometer. "An instrument which makes every action of the arteries apparent to the eye"'” The Lancet, vol. 1, no. 578, pp. 22-27, 1834.

[60] J. B. E. S. Hérisson, To the institute of France. The sphygmometer, an instrument which renders the action of the arteries apparent to the eye; the utility of this instrument in the study of disease, Researches on the affections of the heart, and on the proper means of discriminating themconsidered. Being a Memoir, presented to the Institute of France, Longman, Rees, Orme, Brown, Green, and Longman, London, UK, 1835.

[61] J. B. E. S. Hérisson, Diseases of the heart. The sphygmometer, an instrument which renders the action of the arteries apparent to the eye; the utility of this instrument in the study of disease, Researches on the affections of the heart, and on the proper means of discriminating themconsidered. Being a Memoir, presented to the Institute of France, Longman, Rees, Orme, Brown, Green, and Longman, London, UK, 1835.

[62] W. B. Fye, "Carl Ludwig and the Leipzig Physiological Institute: "A factory of new knowledge"', Circulation, vol. 74, no. 5, pp. 920-928, 1986.

[63] E.-J. Marey, Physiologie médicale de la circulation du sang, basée sur l'étude graphique des mouvements du coeur et $d u$ pouls artériel avec application aux maladies de l'appareil circulatoire, Delahaye, Paris, France, 1863.

[64] "A clinical lecture on the pulse: its diagnostic, prognostic and therapeutic indications," The Lancet, vol. 106, no. 2717, pp. 441-443, 1875.

[65] F. A. Mahomed, "Observations on the circulation made on MR. Weston during his late 500-mile walk," The Lancet, vol. 107, no. 2742, p. 432, 1876.

[66] J. S. Cameron and J. Hicks, "Frederick Akbar Mahomed and his role in the description of hypertension at Guy's Hospital," Kidney International, vol. 49, no. 5, pp. 1488-1506, 1996.

[67] M. F. O'Rourke, "Frederick Akbar Mahomed," Hypertension, vol. 19, no. 2, pp. 212-217, 1992.

[68] F. A. Mahomed, "Remarks on arterio-capillary fibrosis and its clinical recognition.1," The Lancet, vol. 110, no. 2816, pp. 232-234, 1877.

[69] F. Mahomed, "On the sphygmographic evidence of arteriocapillary fibrosis," Transactions of the Pathological Society of London, vol. 28, pp. 394-397, 1877.

[70] C. O. Hawthorne, "The sphygmomanometer and the sphygmograph. In relation to the measurement of arterial blood pressures.1," The Lancet, vol. 177, no. 4564, pp. 424-428, 1911.

[71] C. Bramwell, "The arterial pulse in health and disease," The Lancet, vol. 230, no. 5944, pp. 239-247, 1937.

[72] N. Postel-Vinay, A Century of Arterial Hypertension, 18961996, Wiley, Chichester, UK, 1997.

[73] K. Hirata, M. Kawakami, and M. F. O’Rourke, "Pulse wave analysis and pulse wave velocity-a review of blood pressure interpretation 100 years after Korotkov," Circulation Journal, vol. 70, no. 10, pp. 1231-1239, 2006.

[74] M. F. O’Rourke and J. B. Seward, “Central arterial pressure and arterial pressure pulse: new views entering the second century after Korotkov," Mayo Clinic Proceedings, vol. 81, no. 8, pp. 1057-1068, 2006.
[75] J. S. Mackenzie, Principles of Diagnosis and Treatment in Heart Affections, Henry Frowde, London, UK, 2nd edition, 1916.

[76] Statical essays containing homastatics; or, an account of some hydraulic and hydrostatical experiments made on the blood and blood-vessels of animals. ... To which is added, an appendix, ... With an index to both volumes. Vol. II. By Stephen Hales [computer program]. Version The third edition, correct: London: Wilson and Nicol; T. Durham; G. Keith; and Robinson and Roberts; 1769.

[77] K. H. Parker, "A brief history of arterial wave mechanics," Medical and Biological Engineering and Computing, vol. 47, no. 2, pp. 111-118, 2009.

[78] J. C. Bramwell and A. V. Hill, "Velocity of transmission of the pulse-wave and elasticity of arteries," The Lancet, vol. 199, no. 5149, pp. 891-892, 1922.

[79] J. R. Womersely, "Oscillatory flow in arteries: the constrained elastic tube as a model of arterial flow and pulse transmission," Physics in Medicine and Biology, vol. 2, no. 2, pp. 178187, 1957.

[80] W. Nichols, M. O'Rourke, C. Hartley, and D. McDonald, McDonald's Blood Flow in Arteries: Theoretic, Experimental, and Clinical Principles, New York, NY, USA, 1998, http://catdir.loc.gov/catdir/enhancements/fy0637/97021356-d.html.

[81] M. G. Taylor, "An approach to an analysis of the arterial pulse wave. II. Fluid oscillations in an elastic pipe," Physics in Medicine and Biology, vol. 1, no. 4, pp. 321-329, 1957.

[82] M. F. O'Rourke, “Time domain analysis of the arterial pulse in clinical medicine," Medical and Biological Engineering and Computing, vol. 47, no. 2, pp. 119-129, 2009.

[83] M. F. O’Rourke and A. P. Avolio, "Arterial transfer functions: background, applications and reservations," Journal of Hypertension, vol. 26, no. 1, pp. 8-10, 2008.

[84] A. Avolio, B. E. Westerhof, M. Siebes, and J. V. Tyberg, "Arterial hemodynamics and wave analysis in the frequency and time domains: an evaluation of the paradigms," Medical and Biological Engineering and Computing, vol. 47, no. 2, pp. 107-110, 2009.

[85] A. D. Hughes and K. H. Parker, "Forward and backward waves in the arterial system: impedance or wave intensity analysis?" Medical and Biological Engineering and Computing, vol. 47, no. 2, pp. 207-210, 2009.

[86] O. H. Schmitt, "Mechanism of the excitatory process in biological systems," Office Naval Research progress report 24609, 1955.

[87] G. M. Drzewiecki, J. Melbin, and A. Noordergraaf, "Arterial tonometry: review and analysis," Journal of Biomechanics, vol. 16, no. 2, pp. 141-152, 1983.

[88] M. F. O’Rourke and D. E. Gallagher, "Pulse wave analysis," Journal of Hypertension, Supplement, vol. 14, no. 5, pp. S147S157, 1996.

[89] M. J. Dennis, "Plethysmography: the new wave in haemodynamic monitoring - a review of clinical applications," Australian Critical Care, vol. 13, no. 1, pp. 14-20, 2000.

[90] E. M. Simmons, H. Leader, S. A. Friedman et al., "A computer program for the peripheral pulse wave," The American Journal of Cardiology, vol. 19, no. 6, pp. 827-831, 1967.

[91] E. R. Nye, "The effect of blood pressure alteration on the pulse wave velocity," British Heart Journal, vol. 26, pp. 261265, 1964.

[92] E. Simonson and K. Nakagawa, "Effect of age on pulse wave velocity and "aortic ejection time" in healthy men and in men with coronary artery disease," Circulation, vol. 22, pp. 126129, 1960. 
[93] G. L. Woolam, P. L. Schnur, C. Vallbona, and H. E. Hoff, "The pulse wave velocity as an early indicator of atherosclerosis in diabetic subjects," Circulation, vol. 25, pp. 533-539, 1962.

[94] S. Kogure, R. Hyashi, K. Sakaibori, S. Kurihara, and K. Murata, "Aortic pulse wave velocity in atherosclerotic diseases," American Journal of Medicine, vol. 85, no. 5, p. 739, 1988.

[95] T. Hirai, S. Sasayama, T. Kawasaki, and S. I. Yagi, "Stiffness of systemic arteries in patients with myocardial infarction. A noninvasive method to predict severity of coronary atherosclerosis," Circulation, vol. 80, no. 1, pp. 78-86, 1989.

[96] C. Vlachopoulos, K. Aznaouridis, M. F. O’Rourke, M. E. Safar, K. Baou, and C. Stefanadis, "Prediction of cardiovascular events and all-cause mortality with central haemodynamics: a systematic review and meta-analysis," European Heart Journal, vol. 31, no. 15, pp. 1865-1871, 2010.

[97] B. Williams, P. S. Lacy, S. M. Thom et al., "Differential impact of blood pressure-lowering drugs on central aortic pressure and clinical outcomes: principal results of the Conduit Artery Function Evaluation (CAFE) study," Circulation, vol. 113, no. 9, pp. 1213-1225, 2006.

[98] T. Willum-Hansen, J. A. Staessen, C. Torp-Pedersen et al., "Prognostic value of aortic pulse wave velocity as index of arterial stiffness in the general population," Circulation, vol. 113, no. 5, pp. 664-670, 2006.

[99] S. Laurent, P. Boutouyrie, R. Asmar et al., "Aortic stiffness is an independent predictor of all-cause and cardiovascular mortality in hypertensive patients," Hypertension, vol. 37, no. 5, pp. 1236-1241, 2001.

[100] Z. Dhakam, C. M. McEniery, Yasmin, J. R. Cockcroft, M. J. Brown, and I. B. Wilkinson, "Atenolol and eprosartan: differential effects on central blood pressure and aortic pulse wave velocity," American Journal of Hypertension, vol. 19, no. 2, pp. 214-219, 2006.

[101] R. Asmar, A. Benetos, J. Topouchian et al., "Assessment of arterial distensibility by automatic pulse wave velocity measurement: validation and clinical application studies," Hypertension, vol. 26, no. 3, pp. 485-490, 1995.

[102] M. W. Rajzer, W. Wojciechowska, M. Klocek, I. Palka, M. Brzozowska-Kiszka, and K. Kawecka-Jaszcz, "Comparison of aortic pulse wave velocity measured by three techniques: Complior, SphygmoCor and Arteriograph," Journal of Hypertension, vol. 26, no. 10, pp. 2001-2007, 2008.

[103] N. A. Jatoi, A. Mahmud, K. Bennett, and J. Feely, "Assessment of arterial stiffness in hypertension: comparison of oscillometric (Arteriograph), piezoelectronic (Complior) and tonometric (SphygmoCor) techniques," Journal of Hypertension, vol. 27, no. 11, pp. 2186-2191, 2009.

[104] P. J. Brands, A. P. G. Hoeks, L. Hofstra, and R. S. Reneman, "A noninvasive method to estimate wall shear rate using ultrasound," Ultrasound in Medicine and Biology, vol. 21, no. 2, pp. 171-185, 1995.

[105] R. H. Mohiaddin, D. N. Firmin, and D. B. Longmore, "Agerelated changes of human aortic flow wave velocity measured noninvasively by magnetic resonance imaging," Journal of Applied Physiology, vol. 74, no. 1, pp. 492-497, 1993.

[106] P. J. Brands, J. M. Willigers, L. A. F. Ledoux, R. S. Reneman, and A. P. G. Hoeks, "A noninvasive method to estimate pulse wave velocity in arteries locally by means of ultrasound," Ultrasound in Medicine and Biology, vol. 24, no. 9, pp. 13251335, 1998.

[107] M. E. Safar, O. Henry, and S. Meaume, "Aortic pulse wave velocity: an independent marker of cardiovascular risk,"
American Journal of Geriatric Cardiology, vol. 11, no. 5, pp. 295-304, 2002.

[108] R. W. Stadler, W. C. Karl, and R. S. Lees, "The application of echo-tracking methods to endothelium-dependent vasoreactivity and arterial compliance measurements," Ultrasound in Medicine and Biology, vol. 22, no. 1, pp. 35-42, 1996.

[109] F. Antonini-Canterin, M. Roşca, C. C. Beladan et al., "Echotracking assessment of carotid artery stiffness in patients with aortic valve stenosis," Echocardiography, vol. 26, no. 7, pp. 823-831, 2009.

[110] L. H. Peterson, R. E. Jensen, and J. Parnell, "Mechanical properties of arteries in vivo," Circulation Research, vol. 8, pp. 622639, 1960.

[111] M. F. O’Rourke, "Isolated systolic hypertension, pulse pressure, and arterial stiffness as risk factors for cardiovascular disease," Current Hypertension Reports, vol. 1, no. 3, pp. 204211, 1999.

[112] M. F. O'Rourke, “Arterial aging: pathophysiological principles," Vascular Medicine, vol. 12, no. 4, pp. 329-341, 2007.

[113] S. Madhavan, W. L. Ooi, H. Cohen, and M. H. Alderman, "Relation of pulse pressure and blood pressure reduction to the incidence of myocardial infarction," Hypertension, vol. 23, no. 3, pp. 395-401, 1994.

[114] S. S. Franklin, K. Sutton-Tyrrell, S. H. Belle, M. A. Weber, and L. H. Kuller, "The importance of pulsatile components of hypertension in predicting carotid stenosis in older adults," Journal of Hypertension, vol. 15, no. 10, pp. 1143-1150, 1997.

[115] A. Benetos, M. Safar, A. Rudnichi et al., "Pulse pressure: a predictor of long-term cardiovascular mortality in a french male population," Hypertension, vol. 30, no. 6, pp. 14101415, 1997.

[116] G. F. Mitchell, L. A. Moyé, E. Braunwald et al., "Sphygmomanometrically determined pulse pressure is a powerful independent predictor of recurrent events after myocardial infarction in patients with impaired left ventricular function," Circulation, vol. 96, no. 12, pp. 4254-4260, 1997.

[117] W. G. Walker, J. D. Neaton, J. A. Cutler, R. Neuwirth, and J. D. Cohen, "Renal function change in hypertensive members of the multiple risk factor intervention trial: racial and treatment effects," Journal of the American Medical Association, vol. 268, no. 21, pp. 3085-3091, 1992.

[118] R. Kelly, C. Hayward, A. Avolio, and M. O’Rourke, "Nonivasive determination of age-related changes in the human arterial pulse," Circulation, vol. 80, no. 6, pp. 1652-1659, 1989.

[119] J. Nürnberger, A. Keflioglu-Scheiber, A. M. Opazo Saez, R. R. Wenzel, T. Philipp, and R. F. Schäfers, "Augmentation index is associated with cardiovascular risk," Journal of Hypertension, vol. 20, no. 12, pp. 2407-2414, 2002.

[120] A. Tuttolomondo, R. Di Sciacca, D. Di Raimondo et al., "Arterial stiffness indexes in acute ischemic stroke: relationship with stroke subtype," Atherosclerosis, vol. 211, no. 1, pp. 187-194, 2010.

[121] C. Vlachopoulos, K. Aznaouridis, and C. Stefanadis, "Prediction of cardiovascular events and all-cause mortality with arterial stiffness. A systematic review and meta-analysis," Journal of the American College of Cardiology, vol. 55, no. 13, pp. 1318-1327, 2010.

[122] J. P. J. Halcox, W. H. Schenke, G. Zalos et al., "Prognostic value of coronary vascular endothelial dysfunction," Circulation, vol. 106, no. 6, pp. 653-658, 2002.

[123] T. Murakami and K. Ohsato, "Excess of mortality in patients with endothelial dysfunction," Jounral of American College of Cardiology, no. 6, supplement 2, p. 371, 2003. 
[124] J. Tao, D. H. Liu, L. C. Wang et al., "Arterial elasticity identified by pulse wave analysis and its relation to endothelial function in patients with coronary artery disease," Journal of Human Hypertension, vol. 21, no. 2, pp. 149-153, 2007.

[125] A. E. Donald, M. Charakida, T. J. Cole et al., "Non-invasive assessment of endothelial function. Which technique?" Journal of the American College of Cardiology, vol. 48, no. 9, pp. 1846-1850, 2006.

[126] A. Nohria, M. Gerhard-Herman, M. A. Creager, S. Hurley, D. Mitra, and P. Ganz, "Role of nitric oxide in the regulation of digital pulse volume amplitude in humans," Journal of Applied Physiology, vol. 101, no. 2, pp. 545-548, 2006.

[127] P. O. Bonetti, G. M. Pumper, S. T. Higano, D. R. Holmes, J. T. Kuvin, and A. Lerman, "Noninvasive identification of patients with early coronary atherosclerosis by assessment of digital reactive hyperemia," Journal of the American College of Cardiology, vol. 44, no. 11, pp. 2137-2141, 2004.

[128] J. T. Kuvin, A. R. Patel, K. A. Sliney et al., "Assessment of peripheral vascular endothelial function with finger arterial pulse wave amplitude," American Heart Journal, vol. 146, no. 1, pp. 168-174, 2003.

[129] G. Mancia, G. De Backer, A. Dominiczak et al., "2007 Guidelines for the management of arterial hypertension: the Task Force for the Management of Arterial Hypertension of the European Society of Hypertension (ESH) and of the European Society of Cardiology (ESC)," European Heart Journal, vol. 28, no. 12, pp. 1462-1536, 2007.

[130] M. Munakata, A. Nagasaki, T. Nunokawa et al., "Effects of valsartan and nifedipine coat-core on systemic arterial stiffness in hypertensive patients," American Journal of Hypertension, vol. 17, no. 11, part 1, pp. 1050-1055, 2004. 


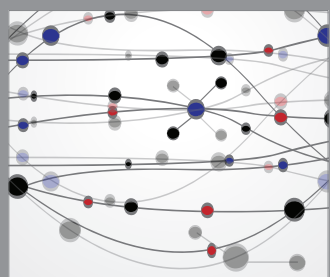

The Scientific World Journal
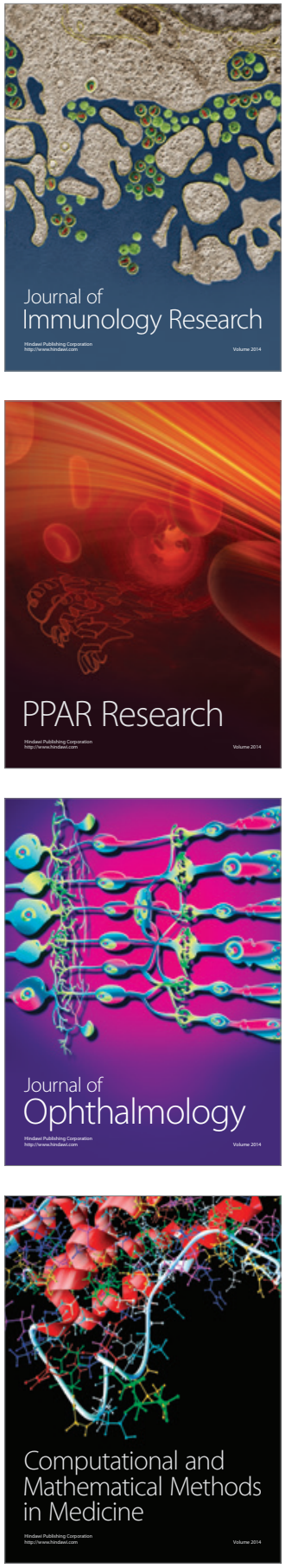

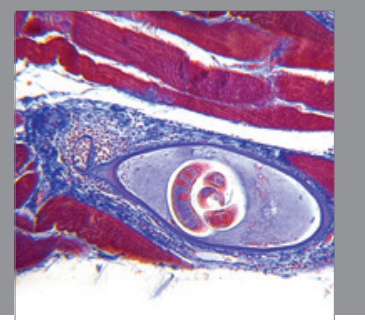

Gastroenterology

Research and Practice
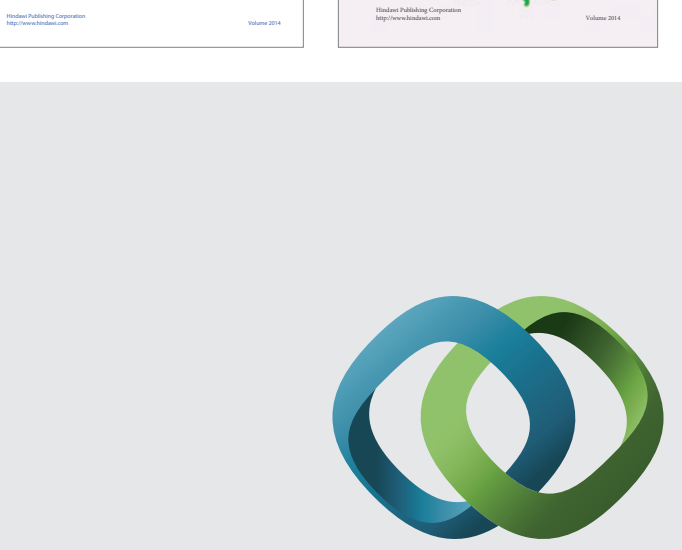

\section{Hindawi}

Submit your manuscripts at

http://www.hindawi.com
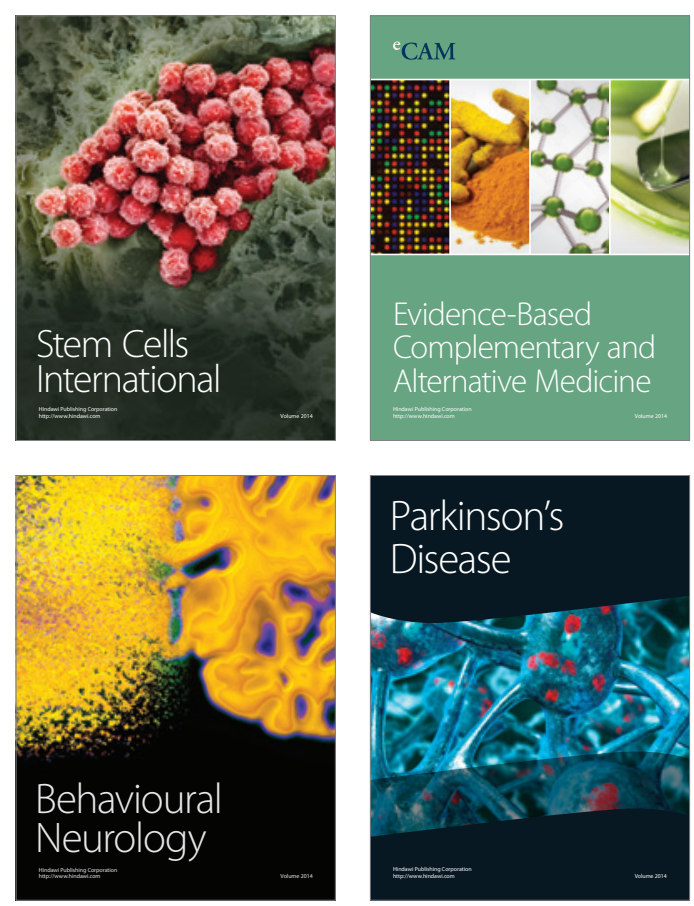

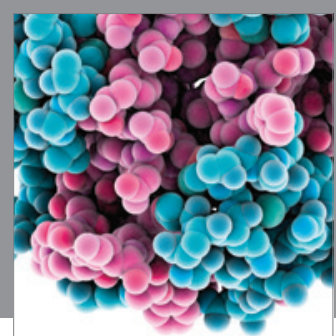

Journal of
Diabetes Research

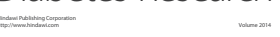

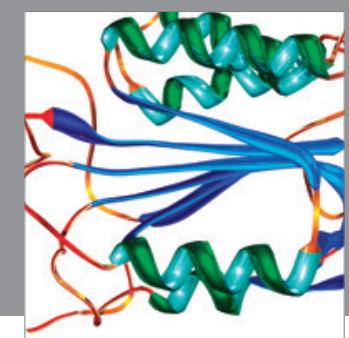

Disease Markers
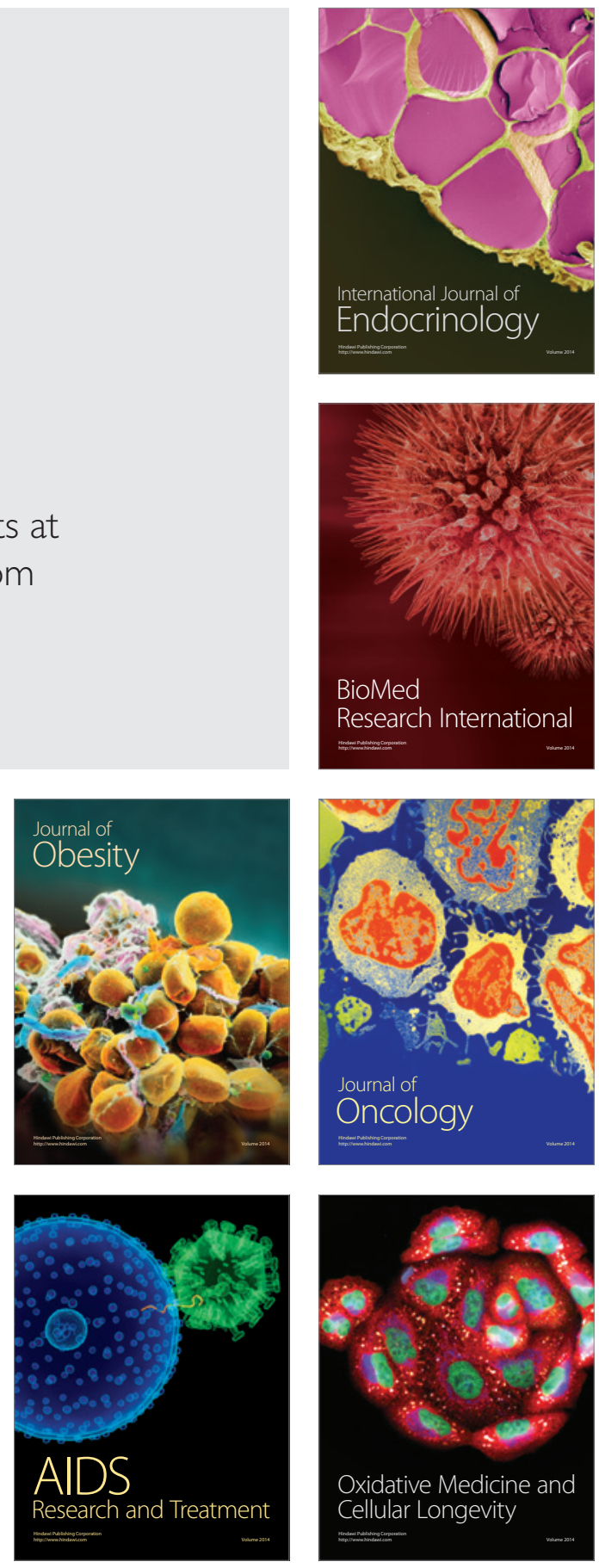